(REVIEW ARTICLE)

\title{
Gut bacteria and human body; a mini review
}

\author{
Ramesa Shafi Bhat ${ }^{1,}{ }^{*}$, Dina A Soliman ${ }^{2}$, Nora A Aljebrin ${ }^{1}$, Leena S Alsuhaibani ${ }^{1}$ and Latifah M Alotebi ${ }^{1}$ \\ ${ }^{1}$ Biochemistry Department, Science College, King Saud University, P.O.Box 22452, Zip code 11495, Riyadh, Saudi Arabia. \\ 2 Microbiology Department Science College, King Saud University, P.O.Box 22452, Zip code 11495, Riyadh, Saudi Arabia.
}

Publication history: Received on 17 September 2019; revised on 23 November 2019; accepted on 26 November 2019

Article DOI: https://doi.org/10.30574/gscarr.2019.1.1.0001

\begin{abstract}
Mammalian gastrointestinal tract is inhabited by microbiota right from the birth to old age. This microbial community is host specific and plays a major role in maintaining host physiology, nutritional status and stress response. Human body is inhabited by $10^{14}$ microorganisms in gastrointestinal tract with higher number of gram-positive Firmicutes and the gram-negative Bacteroidetes. Major amount of gut flora are present in colon part where as stomach bear the smallest amount. Balance between body and the resident bacterial population is very important from health point and if disturbed, it can result into various kinds of disease. This review article will highlights the association of microbiota with the human body along the gastrointestinal tract starting from the mouth, esophagus, stomach, and intestines.
\end{abstract}

Keywords: Gut microbiota; Firmicutes; Bacteroidetes; Gastrointestinal tract

\section{Introduction}

The gut microbiota acts as ecosystem in maintain the homeostasis in host body right from the birth to old age [1-3]. Colonisation in gut of infants starts immediately after birth and its pattern depends mainly on milk feeding type (breast versus formula) and mode of delivery (birth canal versus caesarean section). This stage of life is very important as the pattern of permanent flora in adults depends significantly on colonization pattern at infant stage. Usually gut microbes are nonpathogenic, colonized from mouth to colon, and are mainly involved in regulating metabolism in host body as they are involved in many physiological processes like strengthening intestinal epithelium, immunity, harvesting energy and even giving protection against pathogens [4,5]. Human body inhabits by almost $10^{14}$ microorganisms in gastrointestinal tract (GI tract) with the estimated ratio of 1:1 to human: bacterial cells [6]. The quantity and the composition of gut flora changes along the GI tract and strictly depend on the functions performed at the various parts in body [7-10]. Majority of gut flora consists of Firmicutes and Bacteroidetes which are gram-positive and the gramnegative bacteria respectively and constitutes about $90 \%$ of the gut phyla. However bacteria such as Actinobacteria, Fusobacteria Verrucomicrobia, Proteobacteria, and Cyanobacteria are present at subdominant levels [11]. Upper parts of the GI tract like mouth stomach and small intestine have low number of bacteria as compared with colon which consists of high number of bacteria [12].

\subsection{Mouth}

Mouth is the major gateway of human body and consists of highly diverse microbiota with almost 600 bacterial species and serves as a primary digestive organ where breakdown of dietary carbohydrates and lipids takes place [13]. Diet and personal hygiene plays a very important role in maintain the normal flora in mouth [13-15]. As compared to other parts of the GI tract, mouth has easy access to pathogenic bacteria but it hardly catches infection due to presence of highly effective host-defense mechanisms [16,17]. Salivary glands and epithelial cells in the mouth continuously secrete mucosa with antibacterial properties [18]. Food is chewed and mixed with saliva before entering to stomach.

\footnotetext{
${ }^{*}$ Corresponding author

E-mail address: rbhat@ksu.edu.sa
} 
Saliva contains the microbial communities adhered to tooth, gingival crevices, and tongue dorsum [19]. Usually the oral bacteria present in saliva in planktonic state are not responsible for oral diseases but transmission of pathogenic bacteria with in the mouth is mediated by saliva and can cause a number of oral infectious like tooth decay , periodontitis and tonsillitis [20,21]. Mutans streptococci stands for the primary etiologic agent for dental caries and tooth decay whereas Porphyromonas gingivalis, Tannerella forsythia and Treponema denticola infection leads to periodontitis $[22,23]$. Microbes present in the saliva plays a significant role in host's health status. Microbes present in saliva are mixture of bacterial populations that exist at various sites in the oral cavity, although its community composition is most similar to the tongue microbiota [24-26]. Saliva plays a major role in maintaining the oral health by provide the primary nutrient's required for the development of a balanced microbiome [27, 28]. Salivary components like immunoglobulin A, lactoferrin, lactoperoxidase, lysozyme, statherin and histatins helps in maintaining the balanced microbes in mouth [29]. Oral health is mainly depend on symbiosis which depends on the complex equilibrium between resident species and if this equilibrium is disturbed it can result into disease or dysbiosis [30] . Many factors like dysfunction of salivary glands, poor oral hygiene, gingival inflammation, dietary habits and smoking can result in oral dysbiosis [31, 32].

\subsection{Esophagus}

The esophagus is approximately $25 \mathrm{~cm}$ long tube, responsible for transferring food from the pharynx to the stomach. Its internal mucosa is wet with saliva with pH 7 and mostly contain stratified squamous epithelial layer. As compared to other parts of gastrointestinal tract esophagus mucosa hosts a smaller population of microbes. Human esophagus flora is almost similar to what is present in mouth cavity [33]. Esophageal microbiome mainly constitute of bacteria and yease [34]. Usually the normal esophagous is dominated by Streptococcus spp in addition to low proportion of Prevotella, Fusobacterium, and Veillonella spp [35]. Heightening of some Gram-negative strains like Veillonella, Prevotella, Haemophilus, Neisseria, Campylobacter, and Fusobacterium in this region can results in gastroesophageal reflux disease and even in esophageal precancerous lesion. Overgrowth of Campylobacter species can also contribute towards the occurrence of adenocarcinoma [36].

\subsection{Stomach}

Normally the healthy stomach is sterile due to its $\mathrm{pH}$ less than 2 where most of the microbes cannot survive. Very few bacteria like Streptococcus, Staphylococcus and mainly acid-tolerant lactobacilli can be cultured from the normal stomach [37]. Also helicobacter pylori can colonizes in the gastric mucosa of humans. In some cases its infection can develop serious disease including duodenal ulceration and gastric cancer [38].

\subsection{Intestine}

The number and type of bacteria in small intestine vary with the region; the proximal part mainly has Gram-positive flora among which lactobacilli and Enterococcus faecalis predominate with around $10^{5}-10^{7}$ bacteria per ml of fluid. The number of bacteria gets increased in digital part with around $10^{8}$ bacteria per ml with some additional bacteria's including coliforms (E. coli) and bacteroides, in addition to lactobacilli and enterococci. When we move to large intestine also known as colon; its flora is qualitatively similar to feces. Colon has high number of bacteria as compared to small intestine and is almost $10^{11}$ per $\mathrm{ml}$ of feces. Predominant species found in this region constitute of Coliforms, enterococci, clostridia and lactobacilli with very high number of anaerobic Bacteroides and anaerobic lactic acid bacteria in the genus Bifidobacterium [39]. The gut flora of intestines plays a very important role in protective and metabolic function of the body. Inhabitant flora act as central line of resistance to colonization by exogenous microbes and prevent intestinal mucosa from incoming pathogen. Adherent nonpathogenic bacteria are able to prevent the attachment and entry of pathogens into epithelial cells. Also they compete for available nutrients in ecological niches and thus maintain the collective microenvironment [40]. Some of the important vitamins such as vitamin $\mathrm{K}$ and some B vitamins like folate, B12, and biotin are synthesized by intestinal flora which include Bacteroides, Eubacterium, Propionibacterium, and Fusobacterium [41-43]. Colonic micro flora are also involves in fermentation of nondigestible carbohydrates like resistant starches, pectins, and cellulose in addition to some oligosaccharides that escape digestion and are metabolized to short -chain fatty acids as an end product in the process [44-46]. These sugars are mainly converted to acetate, proprionate, and butyrate. All these fatty acids play a major role in stimulate epithelial cell proliferation and differentiation in the colon [44-48].

\section{Conclusion}

Human body consists of two kinds of bacteria, beneficial and harmful. Healthy body holds balanced and useful bacteria dominate. A beneficial bacterium is able to produce some essential vitamins and organic acids in host body gut and thus 
plays a major role in prevention of disease. These nonpathogenic gut microbes are involved in many physiological processes in body and are colonized right from mouth to colon to keep the body healthy.

\section{Compliance with ethical standards}

\section{Disclosure of conflict of interest}

The authors declare that they have no competing interests

\section{References}

[1] Wells JM, Brummer RJ, Derrien M, MacDonald TT, Troost F, Cani PD, Theodorou V, Dekker J, Méheust A, de Vos WM, Mercenier A, Nauta A and Garcia-Rodenas CL. (2016). Homeostasis of the gut barrier and potential biomarkers. American journal of physiology Gastrointestinal and liver physiology, 312(3), 171-193.

[2] Wu HJ and Wu E. (2012). The role of gut microbiota in immune homeostasis and autoimmunity. Gut microbes. $3(1), 4-14$.

[3] Gagliardi A, Totino V, Cacciotti F, Iebba V, Neroni B, Bonfiglio G, Trancassini M, Passariello C, Pantanella F and Schippa S. (2018). Rebuilding the Gut Microbiota Ecosystem. International journal of environmental research and public health, 15(8), 1679.

[4] Nicholson JK, Holmes E and Wilson ID. (2005). Gut microorganisms, mammalian metabolism and personalized health care. Nat Rev Microbiol, 3, 431-438.

[5] Bik EM. (2009). Composition and function of the human-associated microbiota. Nutr Rev, 67, 164-171.

[6] Sender R, Fuchs S and Milo R. (2016). Revised estimates for the number of human and bacteria cells in the body. PLoS Biol, 14(8), e1002533.

[7] Natividad JMM and Verdu EF. (2013). Modulation of intestinal barrier by intestinal microbiota: Pathological and therapeutic implications. Pharmacol. Res, 69, 42-51.

[8] den Besten G, van Eunen K, Groen AK, Venema K, Reijngoud DJ and Bakker BM. (2013). The role of short-chain fatty acids in the interplay between diet, gut microbiota, and host energy metabolism. J. Lipid Res, 54, 2325-2340.

[9] Bäumler AJ and Sperandio V. (2016). Interactions between the microbiota and pathogenic bacteria in the gut. Nature. 535, 85-93.

[10] Gensollen T, Iyer SS, Kasper DL and Blumberg RS. (2016). How colonization by microbiota in early life shapes the immune system. Science, 352, 539-544

[11] Eckburg PB, Bik EM, Bernstein CN, Purdom E, Dethlefsen L, Sargent M, et al. (2005). Diversity of the human intestinal microbial flora. Science, 308, 1635-1638.

[12] Berg RD. (1996). The indigenous gastrointestinal microflora. Trends Microbiol, 4, 430-435.

[13] Peterson J, Garges S, Giovanni M, Mcinnes P, Wang L, Schloss JA, et al.(2009) The NIH human microbiome project. Genome Res, 19, 2317-2323.

[14] Dewhirst FE, Chen T, Izard J, Paster BJ, Tanner A C, Yu WH, et al. (2010). The human oral microbiome J Bacteriol. 192, 5002-5017.

[15] Sachdeo A, Haffajee AD and Socransky SS. (2008). Biofilms in the edentulous oral cavity J. Prosthodont, 17, 348356.

[16] Dale BA and Fredericks LP. (2005). Antimicrobial peptides in the oral environment: expression and function in health and disease Curr. Issues Mol. Biol. 7(2), 119.

[17] Zasloff M. (2002). Antimicrobial peptides of multicellular organisms Nature, 415(6870), 389-395.

[18] Amerongen A and VeermanSaliva E. (2002). The defender of the oral cavity Oral Dis. 8(1), 12-22.

[19] Takeshita T, Kageyama S, Furuta M, Tsuboi H, Takeuchi K, Shibata Y and Yamashita Y. (2016). Bacterial diversity in saliva and oral health-related conditions: The Hisayama Study. Scientific reports, 6, 22164. 
Ramesa et al. / GSC Advanced Research and Reviews, 2019, 01(01), 031-035

[20] Greenstein G and Lamster I. (1997). Bacterial transmission in periodontal diseases: a critical review. J Periodontol, 68, 421-431.

[21] Kaplan JB. (2010). Biofilm dispersal: mechanisms, clinical implications, and potential therapeutic uses. J Dent Res, 89, 205-218.

[22] Loesche WJ. (1986). Role of Streptococcus mutans in human dental decay. Microbiol Rev, 50, 353-380.

[23] Socransky SS, Haffajee AD, Cugini MA, Smith C and Kent R LJr (1998) Microbial complexes in subgingival plaque. J Clin Periodontol, 25, 134-144.

[24] Spencer P, Greenman J, McKenzie C, Gafan G, Spratt D and Flanagan A. (2007). In vitro biofilm model for studying tongue flora and malodour. J Appl Microbiol, 103, 985-992.

[25] Segata N, Haake SK, Mannon P, Lemon KP, Waldron L, Gevers D, Huttenhower C and Izard J. (2012). Composition of the adult digestive tract bacterial microbiome based on seven mouth surfaces, tonsils, throat and stool samples. Genome Biol, 13, R42.

[26] Mager DL, Ximenez-Fyvie LA, Haffajee AD and Socransky SS. (2003). Distribution of selected bacterial species on intraoral surfaces. J Clin Periodontol, 30, 644-654.

[27] van't Hof W, Veerman EC, Nieuw Amerongen AV and Ligtenberg AJ. (2014)Antimicrobial defense systems in saliva. Monogr Oral Sci, 24, 40-51.

[28] Takahashi N. (2015). Oral Microbiome Metabolism: From “Who are they?" to "What are they doing?" J Dent Res, $94,1628-1637$.

[29] Doel JJ, Hector MP, Amirtham CV et al. (2004). Protective effect of salivary nitrate and microbial nitrate reductase activity against caries. Eur J Oral Sci, 112, 424-428.

[30] Cho I and Blaser MJ. (2012).The human microbiome: at the interface of health and disease. Nat Rev Genet 13, $260-270$.

[31] Marsh PD, Head DA and Devine DA. (2014) Prospects of oral disease control in the future - an opinion. J Oral Microbiol, 6, 26176.

[32] Wu J, Peters BA, Dominianni C et al. (2016). Cigarette smoking and the oral microbiome in a large study of American adults. ISME J, 10, 2435-2446.

[33] E Norder Grusell, G Dahlén, M Ruth, L Ny, M Quiding-Järbrink, H Bergquist and M Bove. (2013). Bacterial flora of the human oral cavity, and the upper and lower esophagus, Diseases of the Esophagus, 26(1), 1, 84-90.

[34] Ajayi TA, Cantrell S, Spann A and Garman KS. (2018). Barrett's esophagus and esophageal cancer: Links to microbes and the microbiome. PLoS Pathog, 14(12), e1007384.

[35] Pei Z, Bini EJ, Yang L, Zhou M, Francois F and Blaser MJ. (2004). Bacterial biota in the human distal esophagus. Proc. Natl. Acad. Sci. U.S.A, 101, 4250-4255.

[36] Di Pilato V, Freschi G, Ringressi MN, Pallecchi L, Rossolini GM and Bechi P. (2016) The esophageal microbiota in health and disease. Ann N Y Acad Sci, 1381(1), 21-33.

[37] Nardone G and Compare D. (2015). The human gastric microbiota: Is it time to rethink the pathogenesis of stomach diseases? United European gastroenterology journal, 3(3), 255-60.

[38] Martin ME and Solnick JV. (2014). The gastric microbial community, Helicobacter pylori colonization, and disease. Gut microbes, 5(3), 345-50.

[39] Swidsinski A, ALadhoff A, Pernthaler S, Swidsinski V, Loening-Baucke M Ortner J, Weber U, Hoffmann S, Schreiber M, Dietel A and H Lochs. (2002) Mucosal flora in inflammatory bowel disease. Gastroenterology, 122, 44-54.

[40] Hooper LV, J Xu PG, Falk T Midtvedt and JI Gordon. (1999). A molecular sensor that allows a gut commensal to control its nutrient foundation in a competitive ecosystem. Proc. Natl. Acad. Sci. USA, 96, 9833-9838.

[41] Bentley RR. (1982). Meganathan:. Biosynthesis of vitamin K (menaquinone) in bacteria. Microbiol. Rev 46, 241280.

[42] Gordon Cooke, John Behan and Mary Costello. Newly identified vitamin K-producing bacteria isolated from the neonatal faecal flora, Microbial Ecology in Health and Disease. 18, 3-4, 133-138. 
[43] Bentley R and Meganathan R. (2006) Biosynthesis of vitamin K (menaquinone) in bacteria. Microbiol Rev. 1982, 46, 241-80.

[44] Frankel WL, W Zhang, A Singh, DM Klurfeld, S Don, T Sakata, I Modlin and JL Rombeau. (1994). Mediation of the trophic effects of short-chain fatty acids on the rat jejunum and colon. Gastroenterology, 106, 375-380.

[45] Peng LZ He W Chen, IR Holzman and J Lin. (2007). Effects of butyrate on intestinal barrier function in a Caco-2 cell monolayer model of intestinal barrier. Pediatr. Res, 61, 37-41.

[46] Robbins GB and Lewis KH. (1940). Fermentation of Sugar Acids by Bacteria. J Bacteriol, 39(4), 399-404.

[47] Valdes Ana M, Walter Jens, Segal Eran and Spector Tim D. (2018). Role of the gut microbiota in nutrition and health BMJ, 361, k2179.

[48] Zhang T, Yang Y, Liang Y, Jiao X and Zhao C. (2018). Beneficial Effect of Intestinal Fermentation of Natural Polysaccharides. Nutrients, 10(8), 1055.

\section{How to cite this article}

Ramesa SB Dina AS, Latifah MA, Leena SA and Nora AA. (2019). Gut bacteria and human body; a mini review. GSC Advanced Research and Reviews, 1(1), 31-35. 